\title{
A new Mississippian hexactinellid sponge from the western Gondwana: Taxonomic and paleobiogeographic implications
}

\author{
Marcelo G. Carrera, Juan Jose Rustán, N. Emilio Vaccari, and Miguel Ezpeleta \\ Acta Palaeontologica Polonica 63 (1), 2018: 63-70 doi:https://doi.org/10.4202/app.00403.2017
}

A Mississippian hexactinellid sponge from the western Argentina improves the extremely poor late Paleozoic sponge records from Gondwana. The sponge is included in the subfamily Thysanodictyinae of family Dictyospongiidae. The new genus and species Minitaspongia parvis is erected, and its well-preserved spicular structure is described in detail representing the first approximation of the spicule assemblage in Thysanodictyinae. The skeleton is clathrate, three-dimensional with at least two ranks of rectangular openings. This first report of this subfamily outside North America represents the best-known hexactinellid and the first dictyosponge record from the Carboniferous of Gondwana. Unlike the occurrences of Thysanodictyinae in North America, with thick skeletons linked to high-energy shallow water settings, Minitaspongia occurs in low-energy water siliciclastic settings related to a cold climate and glacimarine deposits. Accordingly, the complex wall structure of this sponge should not be invoked as a necessary adaptation to high energy and shallow water settings.

Key words: Porifera, Hexactinellida, Reticulosa, Carboniferous, Mississippian, Argentina.

Marcelo G. Carrera [mcarrera@unc.edu.ar], CICTERRA-CONICET

Universidad Nacional de Córdoba, Facultad de Ciencias Exactas Físicas y Naturales, Av. Vélez Sarfield 1611, Ciudad Universitaria, 5016, Córdoba, Argentina. Juan José Rustan [juanjorustan@gmail.com], N. Emilio Vaccari [evaccari@unc.edu.ar ], and Miguel Ezpeleta [miguelezpeleta@gmail.com], CICTERRA-CONICET Universidad Nacional de Córdoba and Universidad Nacional de La Rioja, Av. Luis M. de la Fuente s/n, Ciudad Universitaria, 5300, La Rioja, Argentina.

This is an open-access article distributed under the terms of the Creative Commons Attribution License (for details please see creativecommons.org), which permits unrestricted use, 
distribution, and reproduction in any medium, provided the original author and source are credited.

Faf Full text $(764.1 \mathrm{kB})$ 